\title{
Arc-to-Arc Mini-Sling 1999: A Critical Analysis of Concept and Technology
}

\author{
Paulo Palma
}

Department of Urology, UNICAMP, Sao Paulo, Brazil

\begin{abstract}
Purpose: The aim of this study was to critically review the Arc-to-Arc mini-sling (Palma's technique) a less invasive midurethral sling using bovine pericardium as the sling material.

Materials and Methods: The Arc-to-Arc mini-sling, using bovine pericardium, was the first published report of a minisling, in 1999. The technique was identical to the "tension-free tape" operation, midline incision and dissection of the urethra. The ATFP (white line) was identified by blunt dissection, and the mini-sling was sutured to the tendinous arc on both sides with 2 polypropylene 00 sutures.

Results: The initial results were encouraging, with $9 / 10$ patients cured at the 6 weeks post-operative visit. However, infection and extrusion of the mini-sling resulted in sling extrusion and removal, with 5 patients remaining cured at 12 months.

Conclusion: The Arc-to-Arc mini-sling was a good concept, but failed because of the poor technology available at that time. Further research using new materials and better technology has led to new and safer alternatives for the management of stress urinary incontinence.
\end{abstract}

Key words: urinary incontinence; stress; sling; arc-to-arc mini-sling; bovine pericardium

Int Braz J Urol. 2011; 37: 252-8

\section{INTRODUCTION}

The understanding of stress urinary incontinence (SUI) pathophysiology has consistently improved over the past decade, and has resulted in the development of many surgical techniques. Based on the Integral Theory, Petros and Ulmsten proposed the tension-free vaginal tape (TVT). According to this theory a mid-urethral tape can stabilize the urethra during straining without modifying urethral mobility $(1,2)$. Despite the good cure rate reported for TVT, major complications as injuries to the bowel and major blood vessels have been described (3).

As an alternative to the TVT procedure, the transobturator tape (TOT) technique was developed by Delorme in 2001, to reduce the perioperative complications related to penetration in the retropubic space (4). Several short-term studies reported high cure rates and low complication rates for TOT, and discussed the mechanism responsible for the success of this treatment based only on preoperative urodynamic findings and postoperative clinical examination, uroflowmetry and the cough test. The continence rate with the transobturator approach was similar to those obtained with the transvaginal retropubic approach (5). Most of the described complications were related to the blind nature of these procedures (6).

The aim of this paper is to report the initial results and complications of the Arc-to-Arc mini-sling (ATAM); then to critically analyze the ATAM tech- 
nique, the materials used (7), and finally, to compare and contrast the ATAM as regards subsequent minislings.

\section{MATERIALS AND METHODS}

\section{Patients}

An open prospective non-randomized clinical trial involving SUI patients was conducted after receiving the approval of the Hospital Ethics Committee. Ten patients (mean age - 58 years) underwent the Arc-to-Arc mini-sling (ATAM) procedure for SUI. The procedures were performed between March 1997 and October 1998.

\section{Study Design}

All patients were given a routine work-up for incontinence, including history, physical examination, stress test and urodynamic investigation. Urodynamic evaluation was performed with 2 urethral catheters (one $10 \mathrm{~F}$ for filling and another $4 \mathrm{~F}$ for bladder pressure measurement). A rectal $4 \mathrm{~F}$ catheter-balloon was placed above the anal sphincter to obtain abdominal pressure. The test included water cystometry, Valsalva leak point pressure assessment, which was performed with an intravesical volume of $200 \mathrm{~mL}$ and Valsalva maneuvers, and pressure-flow study.

The stress test was positive in all patients. $\mathrm{Pa}$ tients who presented involuntary detrusor contractions during bladder filling or Maximum flow (Qmax) less than $15 \mathrm{~mL} / \mathrm{s}$ and/or post void residual urine of more than $20 \%$ of the volume voided were excluded from the study but those with irritative symptoms without urodynamically proven involuntary contractions were included. Although urodynamically proven detrusor instability does not have a significant effect on surgical outcome, this decision was based on the concept regarding the postoperative improvement of sensory urgency, as described previously.

Follow-up was performed at 1,6 and 12 months. During each consultation, the patients were questioned about presence of spontaneous voiding, involuntary urinary leakage, lower urinary tract symp- toms, vaginal and suprapubic pain, and underwent a stress test. The patients were considered subjectively dry in the absence of incontinence, improved, when the incontinence episodes were less than once in two weeks and when incontinence episodes were more than once a week the patients were recorded as subjective failures.

\section{SURGICAL TECHNIQUE}

The procedure is performed with the patient in the lithotomy position. An $18 \mathrm{~F}$ Foley catheter is introduced for safety. A inverted $U$ vaginal incision is made at the level of the bladder neck. The vaginal wall is dissected from the underlying peri-urethral fascia, bilaterally to the inferior ramus of the pubic bone. The urethra is identified and a small perforation of the endopelvic fascia was made at the border of the ascending ramus of the pubic bone bilaterally (Figure-1).

Next, the surgeon's index finger is introduced into the Retzius space towards the obturator internus muscle in order to identify the white line (Figure2).

Once the white line is identified, 2 polypropylene 00 stitches are placed in the tendinous arc at both sides (Figure-3).

Then a mini-sling of bovine pericardium 6 $\mathrm{cm}$ long and $2 \mathrm{~cm}$ width is used to create an ATAM, providing backboard support to the urethra (Figure$4)$.

The vaginal incision is closed in the usual manner and a Foley catheter is left in place overnight.

\section{RESULTS}

There were no vascular or visceral lesions, or any urinary retention.

Nine out of 10 patients were cured of the incontinence at the first postoperative month. After 2 months 2 patients presented infection of the minisling that were removed, late complications included 3 more patients who presented extrusion of the sling at 6 month. The remaining five patients did well and were 


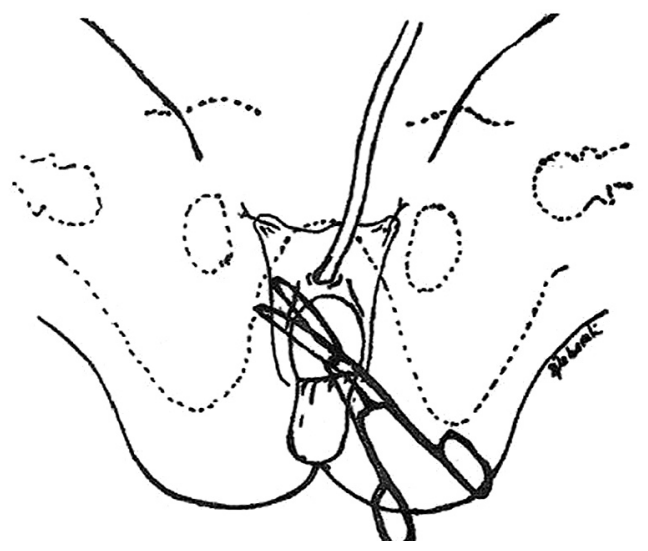

Figure 1 - An inverted U shape incision is made and a Metzenbaum scissors is used to dissect the vaginal wall (original illustrations).

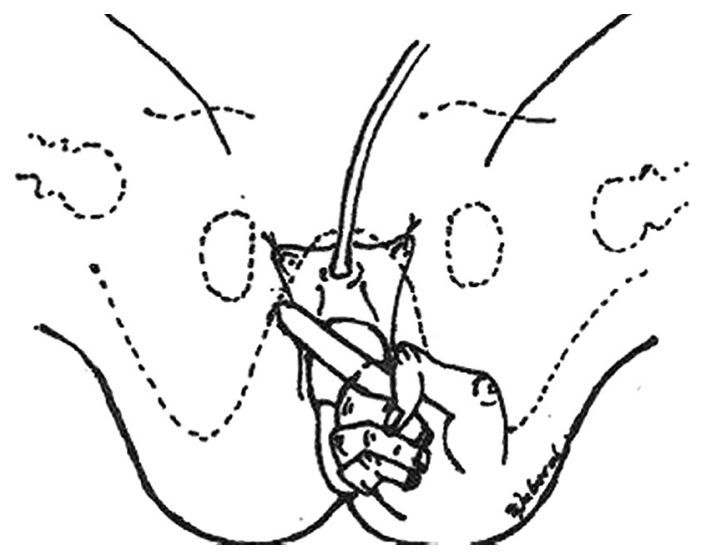

Figure 2-Digital identification of the arcus tendineous fascia pelvis (ATFP).

continent after 12 months. All but one patient that had the mini-sling removed were incontinent accounts for $50 \%$ of good results after one-year follow-up.

\section{COMMENTS}

The understanding of physio-pathological concepts of stress urinary incontinence has consistently improved over the last years and their applications have led to the development of many surgical techniques.
In the past decade minimally invasive synthetic slings, such as TVT, have become the preferred technique, replacing the Burch colposuspension for the treatment of SUI (8).

Various factors have contributed to the popularization of slings, among them, the fact that needle suspensions have not stood the test of time, together with the various paradigm changes and the evolution of biomaterials (1).

Synthetic slings present several advantages over autologous slings.

Harvesting the graft, a time consuming stage of the conventional technique is eliminated along with its related morbidity and a well-standardized

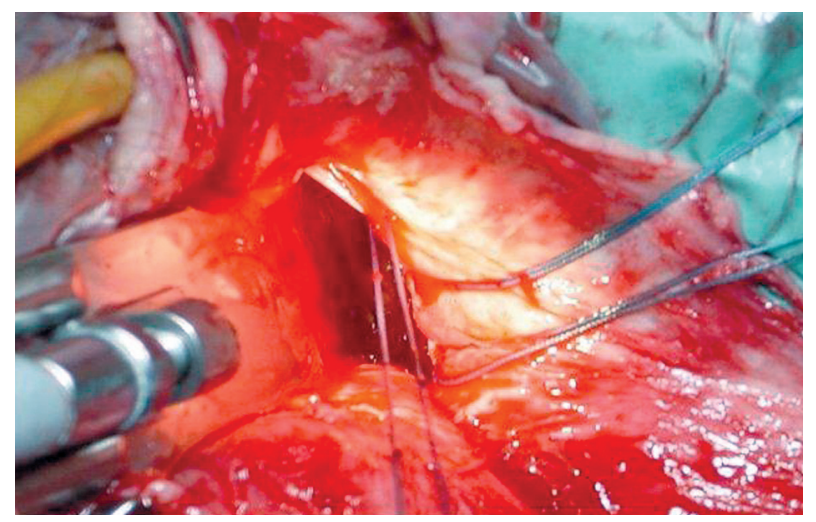

Figure 3 -Sutures placed in the white line (ATFP).

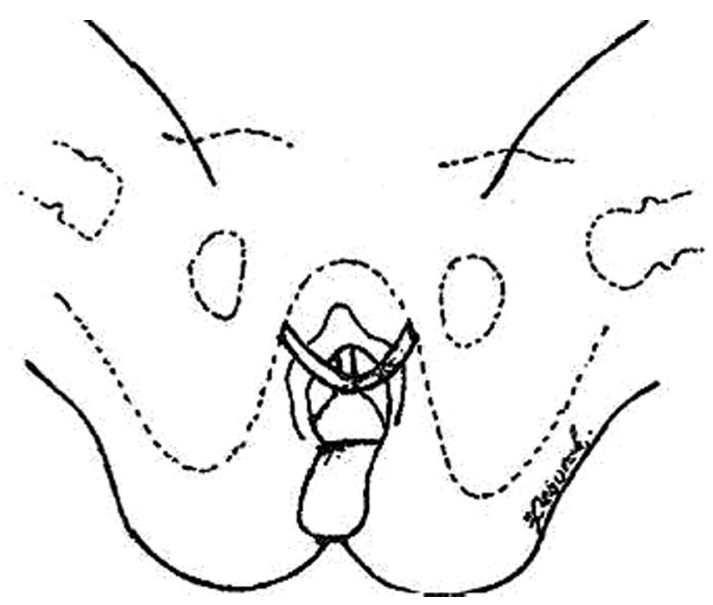

Figure 4 - Suburethral mini-sling anchored to the obturator internus muscles at the level of tendinous arc bilaterally. 
procedure is obtained. Moreover, it may be performed under local anesthesia as an outpatient procedure. Not to mention less post-operative pain and shorter sick leave (2).

On the other hand, synthetic slings have brought about new complications related to the tape and even fatal complications (3).

As an alternative to the TVT procedure, the transobturator tape (TOT) technique was developed by Delorme in 2001. This procedure reduces per-operative complications related to the penetration in the retropubic space (4). Several short-term studies have reported high cure rates and low complication rates for TOT.

However, as with any form of surgery, adverse events can occur, and the surgeon should be aware of the common complications that can accompany sling surgery, and how to best manage them (3).

The most common complication reported with sling surgery is bladder perforation during needle passage. Bladder perforation usually occurs on the side opposite the surgeon's dominant hand, and with greater frequency in patients undergoing repeat procedures.

Many studies have reported an incidence of bladder perforation of between 1-15\%, and an average perforation rate of $5 \%$. Management of bladder perforation includes recognition of the injury during cystoscopy, withdrawal and repositioning of the needle and a Foley catheter for 24 to 48 hours.

Transobturator sling, on the other hand presents a lower rate of bladder and urethral injury during the needle passage, which generally occurs in less than $1 \%$ of patients, usually during the learning curve of the procedure.

Bleeding is another important complication and can occur mainly during needle passage. Bleeding upon entry into the retropubic space can be difficult to manage, as exposure of the perivesical venous plexus is difficult.

Care must be taken during lateral replacement of needles to avoid injuring the external iliac vein for vascular injuries are usually caused by excessive lateral passage of the needle.

Despite the good results described worldwide, with cure rates of more than $80 \%$ of the cases, some major complications like bowel, vascular injuries and deaths have been reported (3).
Most of the described major complications are related to the blind nature of these procedures (6). In fact, reducing needle diameter alone was not enough to overcome these problems that occurred even with experienced surgeons.

In an attempt to reduce major complications, mainly deaths, anatomical reconstruction of the urethral support placing a low-tension suburethral tape anchored to the obturator internus muscles bilaterally at the level of the tendineous arc, the Tissue Fixation System (TFS) was described (6). By doing so, bowel lesions and major vessels injury are avoided.

A decade ago, we used this good technical procedure, but poor technology in biomaterials at that time led to less than optimal results due to an unacceptable extrusion rate.

Insisting on the principle of restoring the urethropelvic ligament, we used the porcine small intestine submucosa in 25 patients in 2001 (9).

Long-term results with the Arc-to-Arc minisling using swine intestine submucosa, produced $60 \%$ of good results after six years follow-up (10).

Although the concept was good and the biomaterial improved, the absence of an appropriate anchoring system and delivery instruments were a major drawback to its widespread use.

The first commercially available kit, was the TFS described by Petros and Richardson. This kit contained two polypropylene anchors and a multifilament mesh. Preliminary report described similar cure rates and fewer complications when compared to TOT (6). These preliminary studies reported no pain, mesh exposure, vascular or visceral complications. No doubt a remarkable achievement.

Long term follow-up with TFS reported good cure rates after 3 years (11) and good technology available today permitted the use of the TFS System to perform uterus sparing procedures as well (12).

Many other devices are now available, some of them depending on mesh integration for the fixation, like TVT-Secur and therefore presenting up to $60 \%$ of failure in the first post-operative year (13).

Primary fixation of mini-slings is a key issue for success, and our experimental data suggests that Ophira and TFS presents the best primary fixation when compared to other mini-slings (14). 
However, needless to say that even minimally invasive procedures require a learn period and failure is an important complication as well.

At this point in time, all we can say is that after many years of research and development we now have good concepts and good technology.

\section{CONCLUSION}

Mini-slings are here to stay and further evidence is being gathered to determine its useful place in the surgeon's armamentarium.

\section{CONFLICT OF INTEREST}

None declared.

\section{REFERENCES}

1. Petros PE, Ulmsten UI: An integral theory and its method for the diagnosis and management of female urinary incontinence. Scand J Urol Nephrol Suppl. 1993; 153: 1-93.

2. Ulmsten U, Henriksson L, Johnson P, Varhos G: An ambulatory surgical procedure under local anesthesia for treatment of female urinary incontinence. Int Urogynecol J Pelvic Floor Dysfunct. 1996; 7: 81-5; discussion 85-6.

3. Deng DY, Rutman M, Raz S, Rodriguez LV: Presentation and management of major complications of midurethral slings: Are complications under-reported? Neurourol Urodyn. 2007; 26: 46-52.

4. Delorme E. Transobturator urethral suspension: miniinvasive procedure in the treatment of stress urinary incontinence in women. Prog Urol. 2001; 11: 1306-13.

5. Palma P, Riccetto C, Herrmann V, Dambros M, Thiel M, Bandiera S, et al.: Transobturator SAFYRE sling is as effective as the transvaginal procedure. Int Urogynecol J Pelvic Floor Dysfunct. 2005; 16: 487-91.

6. Petros PE, Richardson PA: Midurethral Tissue Fixation System sling -- a 'micromethod' for cure of stress incontinence -- preliminary report. Aust N Z J Obstet Gynaecol. 2005; 45: 372-5.

7. Palma P: Tendineouvaginal sling of bovine pericardium (Palma's technique): initial experience. J. Bras. Ginec. 1999; 109: 93-7.
8. Palma P: A requiem to the Burch. Int Urogynecol $\mathbf{J}$ Pelvic Floor Dysfunct. 2007; 18: 589-90.

9. Palma PC, Riccetto CLZ, Herrmann V, Dambros M, Mesquita R, Netto NRJr: Tendinous vaginal support (T.V.S.) using the porcine small intestine submucosa (SIS): a promising anatomical approach for urinary stress incontinence. J Urol. 2001; 165: 5(A).

10. Palma P, Riccetto C, Fraga R, Martins M, Reges R, de Oliveira M, Rodrigues Netto N Jr: Long term followup of the tendinous urethral support: an anatomical approach for stress urinary incontinence. Actas Urol Esp. 2007; 31: 759-63.

11. Petros PE, Richardson PA: Midurethral tissue fixation system (TFS) sling for cure of stress incontinence--3 year results. Int Urogynecol J Pelvic Floor Dysfunct. 2008; 19: 869-71.

12. Inoue H, Sekiguchi Y, Kohata Y, Satono Y, Hishikawa $\mathrm{K}$, Tominaga T, et al.: Tissue fixation system (TFS) to repair uterovaginal prolapse with uterine preservation: a preliminary report on perioperative complications and safety. J Obstet Gynaecol Res. 2009; 35: 34653.

13. Cornu JN, Sèbe P, Peyrat L, Ciofu C, Cussenot O, Haab F: Midterm Prospective Evaluation of TVTSecur Reveals High Failure Rate. Eur Urol. 2010; 23. [Epub ahead of print].

14. Palma P, Siniscalchi R, Riccetto C, Maciel L, Miyaoka, Bigozzi M, et al.: Primary fixation of mini sling:a comparative study "in vivo". Actas Urol Esp. 2010; in press.

Accepted after revision:

July 30, 2010

\section{Correspondence address:}

Dr. Paulo Palma

Department of Urology, UNICAMP

Rua Vital Brasil, $2512^{\circ}$ andar

Cidade Universitária Zeferino Vaz

Campinas, SP, 13083-888, Brazil

Fax: + $55113521-7481$

E-mail:ppalma@uol.com.br 


\section{EDITORIAL COMMENT}

The "Arc-to-Arc" mini-sling procedure was published by Professor Palma in 1999 (1). From a purely anatomical perspective, this procedure is identical to Delorme's 2001 transobturator (TOT) operation (2), and it is conceptually similar to the first anchor- dependent mini-sling (3), which it also precedes by some years.

However, this editorial concerns more than intellectual primacy. It concerns scientific tradition and scientific method. A Western metaphor for the classical Latin epigram quoted by Isaac Newton "nanos gigantium humeris insidentes" is "One who develops future intellectual pursuits by understanding the research and works created by notable thinkers of the past". This concept, understanding, challenging, and building on pre-existing science, lies at the very core of Professor Palma's scientific career. Professor Palma was one of the first to apply the TOT method for stress incontinence using a polypropylene tape (2), was one of the first to apply the posterior sling, "infracoccygeal sacropexy" (4) all the various suspended mesh tapes based on these surgical approaches $(2,4)$, and most recently, tensioned tape mini-slings $(3,5)$.

Palma et al., having examined the evidence, challenged the fundamental cornerstone of urodynamics in their now famous editorial, "The Dark Side of Urodynamics" (6). As regards mini-slings, they tested the gripping power of all commercial mini-slings using an animal model. No concept is accepted. It must be tested for truth or falsity.

In the best scientific tradition, Palma and his colleagues challenged several predictions of the Integral Theory (7). They developed a series of videos demonstrating how support of specific ligaments, such as the pubo-urethral ligament, would control urine loss during coughing in a patient with stress incontinence.

The "Arc-to-Arc" mini-sling paper (1) is another classical example of hypothesis testing. The "Arc-to-Arc" mini-sling operation tested the Integral Theory's prediction (7) that a loose ligament (or tape) at mid-urethra invalidated the oppositely acting closure muscles responsible for distal and proximal urethral closure. One important scientific aspect of Palma's methodology, is that his operation approached the hypothesis from a different direction, by providing a horizontal anchoring point. The importance of this is that the original theory postulated that the mid-urethral insertion point worked by acting as an anchoring point for the muscles, not as a constrictor of the urethral lumen, as has been claimed by some investigators. It is almost impossible to constrict the urethra with a horizontal tape. Nine out of 10 patients were cured at the 6 weeks post-operative visit, clear evidence that at least in an anatomical sense, the surgical restoration had been successful, and the hypothesis validated.

The "Arc to Arc" mini-sling paper, indeed the whole of Professor Palma's scientific career, provides an outstanding example for younger researchers as to how to pursue good science. We need to contrast this with what is not good science, the politicizing of the scientific process, statements by "expert committees" presented as "science", "validation" of questionnaires (whose function really is only to detect symptoms), creation of artificial constructs such as "quality of life", simplistic "sexual satisfaction questionnaires", use of increasingly arcane artificial languages comprehensible only to few practicing clinicians. All of these initiatives according to Karl Popper, the most eminent scientific philosopher of the 20th century, only impoverish science.

For example, if a woman loses $100 \mathrm{gm}$ of urine in 24 hours (an objective scientific measure), she has a poor quality of life ("QoL"). If she is cured by a posterior sling, her good quality of life is suddenly transformed. Yet many contemporaneous papers published in high impact journals use incomprehensible "QoL" scores (and there are tens of them out there) with no mention of the 24 hour urine loss. Such papers are entirely subjective, and belong to the social sciences. One patient may complain bitterly of a $2 \mathrm{gm} / 24$ hour urine loss; another may cheerfully put up with a 1000 gm loss. These are examples, extreme, certainly, but actual. Such a QoL may be deemed to measure a patient's attitude, not the severity of the problem itself. As scientists we need to follow Ockham's* (or Occam's) Razor, which basically emphasizes simplicity as a tool of 
scientific truth. One purpose of medical science is to develop new therapies for patients. We have to not only test and validate these new directions, but be able to meaningfully teach them to others.

Science has to be rigorous, based on clearly defined objective findings. However, objective science also has its failings. A patient's "objective" findings may vary wildly, especially parameters such as urine flow which ultimately depend on urethral resistance, which in turn, is consequent to the 4th power of Poiseuille's law.

One major future challenge is how to assess human variation, an almost impossible task, given that the control mechanisms of the body are non-linear (8). Another challenge is how to meaningfully apply published scientific papers based on large series. These only give general results, not necessarily applicable to a specific individual. Good clinical medicine is about weighing all the evidence for a particular individual (including such studies), plus the modifying factors of the patient's individual condition. As concerns surgery, above all, surgery has to be based on a profound knowledge of dynamic anatomy, and how a particular patient's problem relates to this.

* William of Okham, a 14th Century English philosopher.

\section{REFERENCES}

1. Palma P: Tendineouvaginal sling of bovine pericardium (Palma's technique): initial experience. J. Bras. Ginec. 1999; 109: 93-7.

2. Delorme E: La Bandelette transobturatrice: un procede mininvasif pour traiter l'incontinence urinaire d'effort de la femme. Progres en Urologie 2001. 11; 1306-1313

3. Petros PE, Richardson PA: Midurethral Tissue Fixation System sling -- a 'micromethod' for cure of stress incontinence -- preliminary report. Aust N Z J Obstet Gynaecol. 2005; 45: 372-5.

4. Petros PE: New ambulatory surgical methods using an anatomical classification of urinary dysfunction improve stress, urge and abnormal emptying. Int Urogynecol J Pelvic Floor Dysfunct. 1997; 8: 270-7.

5. Petros PE, Richardson PA: TFS posterior sling improves overactive bladder, pelvic pain and abnormal emptying, even with minor prolapse - a prospective urodynamic study. Pelviperineology. 2010: 29: 52-5.

6. Palma P, Herrmann V: Urodynamics and stress urinary incontinence: the dark side of a gold standard. Int Urogynecol J Pelvic Floor Dysfunct. 2007; 18: 1385-6.

7. Petros PE, Ulmsten UI: An integral theory and its method for the diagnosis and management of female urinary incontinence. Scand J Urol Nephrol Suppl. 1993; 153: 1-93.

8. Petros P: Non-linearity in clinical practice. J Eval Clin Pract. 2003; 9: 171-8.

Professor Dr. Peter Petros Department of Surgery Royal Perth Hospital Perth, Australia E-mail:kvinno@highwayl.com.au 